\title{
Extraction, Preparation and Characterization: Nanocellullose
}

\author{
Mandeep Kaur ${ }^{1}$, Praveen Sharma ${ }^{1}$, Santosh Kumari ${ }^{2}$ \\ Department of Environmental Science \& Engineering ${ }^{1,1}$ \\ Department of Bio \& Nano Technology ${ }^{2}$ \\ Guru Jambheshwar University of Science \& Technology, Hisar \\ Email: mandeepkaur76[at]gmail.com
}

\begin{abstract}
Nanocellulose the organic nanomaterial is an emerging and promising material with exceptional properties and a broad spectrum of potential applications in numerous fields, i.e. pharmaceutics, biomedical, food ingredients, cosmetic additives, packaging materials, hygiene products, film and absorbance media, electronics, barrier films, membranes, nanocomposites and supercapacitors etc. Due to its unique structural features and remarkable physicochemical properties such as biodegradability, biocompatibility, renewability, low density, optical transparency, adaptable surface chemistry and improved mechanical properties nanocellulose has drawn tremendous attention in academia as well as in industrial sector. The main aim of this article is to provide an overview of recent research in the field of nanocellulose production from different pre treatments and methods.
\end{abstract}

Keywords: Nanocellulose, Renewable, Production, Processes

\section{Introduction}

Cellulosic materials (cellulose, hemicelluloses and lignin) due to their unique characteristics viz. biodegradability and renewability, low cost as well as low carbon dioxide release (Abdul Khalil et al., 2016) have been categorized as sustainable, green and environmental friendly materials (Maleki et al., 2017). Utilization of these cellulosic materials generated from different agricultural wastes to produce nanocellulose is a feasible approach (Elias et al., 2017).

The nanocellulose obtained from such biomaterials are equipped with superior characteristics which are high surface area, nanoscale dimension, high crystallinity, optical properties and stiffness alongwith biodegradability and renewability (Siro 2010; Abraham et al., 2011; Trache et al., 2017) and they also combine significant properties of cellulose such as crystalline structure, hydrophilicity and broad chemical modification (Mahfoudhi \& Boufi 2016). Reallocation from cellulose to nanocellulose based materials is a productive method so far (Kalia et al., 2014; Khalil et al., 2014).

Cellulose is the most abundant polymer which is renewable and biodegradable (Jabbar et al., 2017). Cellulose is a linear homopolysaccharide composed of $\beta$ D-glucopyranose units linked together by $\beta$-1-4-linkages ( Kumar et al., 2014). Each $\beta$-1-4 glucopyranose bears three hydroxyl groups where the primary $\mathrm{OH}$ group is located at the $\mathrm{C}-6$ position and the secondary $\mathrm{OH}$ group is located at the $\mathrm{C}-2$ and $\mathrm{C}-3$ position. The secondary and the primary hydroxyl groups of the anhydro-glucose rings are the basis for extensive intra and intermolecular hydrogen bonding (Alemdar \& Sain 2008) allowing the formation of highly ordered three-dimensional crystal structures; therefore making cellulose a semi-rigid polymer. As, Cellulose is linked by $\beta(1 \rightarrow 4)$ glycosidic linkage in a long chain therefore its properties are directly related to the chain length (Horn et al., 2012). One of the properties of cellulose is water insoluble, due to its glycosidic linkage between the monomers. Cellulose derived from plants has hemicellulose, lignin, pectin and other substances.

Hemicellulose is a branched amorphous polysaccharide that comprises about $20 \%$ of the biomass of most plants. In addition to glucose hemicellulose is derived from several sugars like mannose, galactose, rhamnose, arabinose and especially xylose ( Moran et al., 2008). Lignin the most abundant plant-derived amorphous polymer is an organic substance having dendridic network of phenyl propane which bind the cells, fibres and vessels which constitute wood and the lignified elements of plants. After cellulose, it is the most abundant renewable carbon source on earth. Lignin is a complex molecular structure containing crosslinked polymers of phenolic monomers especially pcoumaryl alcohol, coniferyl alcohol and sinapyl alcohol. Pectin is a heteropolysaccharide of 1-4 linked galacturonic acid with methyl esters of different sugar units (Klemm et al., 1998; Eichhorn et al., 2001).

In plant cell wall structure, crystal and amorphous cellulose structure form nano/micro fibers, which together produce cellulose fiber (Eichhorn et al., 2010). Therefore, cellulose contains highly ordered crystalline alternative with less ordered amorphous segments (Sjostrom E 1993). The amorphous segments can be removed to produce highly crystalline cellulose (Azizi et al., 2005). Cellulose occurs in four major polymeric forms: cellulose I, II, III and IV (Giri \& Adhikari 2013). Among them cellulose I is natural cellulose with structures $\mathrm{I}_{\alpha}$ and $\mathrm{I}_{\beta}$. Cellulose $\mathrm{I}_{\alpha}$ has a single chain triclinic structure and $I_{\beta}$ has two chain monoclinic structure (Kukle et al., 2011). Cellulose in regenerated cellulose fibers is cellulose II that can be formed whenever the lattice of cellulose I is destroyed as on swelling with strong alkali or on dissolution of cellulose (Kamel 2007). The conversion of cellulose I to cellulose II is irreversible, suggesting that cellulose I is metastable and cellulose II is stable. With various chemical treatments it is possible to produce the structures of cellulose III on heating cellulose I and II with ammonia and cellulose IV on heating cellulose III ( Park et al., 2010).

\section{Volume 6 Issue 12, December 2017}

\section{www.ijsr.net}




\section{International Journal of Science and Research (IJSR) \\ ISSN (Online): 2319-7064 \\ Index Copernicus Value (2016): 79.57 | Impact Factor (2015): 6.391}

\section{Overview of cellulosic materials}

Cellulose microfibrils are the elementary components of cellulose formed during the biosynthesis (Chirayil et al., 2014). The term microfibril is generally used to describe the 2-10 nm thick fibrous cellulose structures with the length of several microns. Depending on the basis of dimensions, functions and preparation methods nanocellulose can be classified in two categories cellulose nanocrystals $(\mathrm{CNC})$ and cellulose nanofibres (CNFs).

Cellulose nanofibres (Abe et al., 2003) and nanofibrils ( Xie \& Li 2017 ; Henriksson et al., 2008) are the terms used for microfibrillated cellulose ( Siqueria et al., 2010).

Cellulose nanocrystals (Azeredo et al., 2016) are rod-like nanoparticles with limited flexibility as they do not contain amorphous regions (Brinchi et al., 2013). Other names for nanocrystals are nanowhiskers (John \& Thomas 2008; Oksman 2006), nanorods (Dujardin et al., 2003) and rodlike nanocystals (Iwamoto et al., 2007). CNCs are the crystalline regions of the CNFs which under controlled conditions can lead to the formation of high-purity crystals (Azizi et al., 2005). Due to this its elastic modulus can be equivalent to the modulus of crystalline cellulose up to 140 GPa ( Jonoobi et al., 2015).

\section{Preparation of nanocellulose}

Generally, preparation of nanocellulose is carried out in two steps. The first step involves the pretreatment of raw material (depending upon the source) to produce purified individual cellulosic fibres that can be further processed. The second step is the transformation of individual cellulosic fibres into microfibrils, nanofibres or nanocrystals (Garcia et al., 2015). Various methods have been suggested by different researchers to synthesize nanocellulose.

\section{Enzymatic Hydrolysis}

To understand the enzymatic hydrolysis of cellulose, most significant is (i) the structural behavior of cellulosic biomass and (ii) biological barriers for enzyme interactions. Enzymes introduced desired functional groups on the surface of nanocelluloses (Karim et al., 2015). Enzymes are employed to alter hemicelluloses and lignin contents while maintaining cellulose portion (Janardan \& Sain 2006 ; Khalil et al., 2014). Enzymatic treatments facilitate the fabrication of cellulose nanocrystals with reduced energy consumption. The enzymes involved are cellobiohydrolases and endoglucanases. Cellobiohydrolases (the main enzymes) are able to attack highly crystalline cellulose and endoglucanases require some disorder in the structure to perform cellulose degradation. These enzymes show strong synergistic effects (Henriksson et al., 2007).

\section{Oxidation}

The TEMPO-mediated (2,2,6,6-tetramethyl-1-piperidine1-oxyl) oxidation is the most widely used method to isolate nanofibres or nanocrystals. The carboxylate and aldehyde functional groups are put into the $\mathrm{C}_{6}$ glucose unit of cellulose structure under moderate conditions (Iwamoto et al., 2011). A primary oxidizing agent (sodium hypochlorite) and an additional catalyst sodium bromide or an iodine are employed at pH 9-11(Saito et al., 2009).

\section{Electrospinning}

Electrospinning is simple, efficient and cost effective processes which formulate nanofibres from non-woven to the order of few nanometers with advanced mechanical properties, large surface area and ease of functionalisation. UV irradiation in concentrated crystalline liquid solutions containing isotropic solvents like acetone, ethanol, methanol, dimethylformamide or water are generally used (Christoforou 2010). Over the past few years, there has been a tremendous intensification of the research activities to explore electrospinning for nanofibers formation involving a large variety of materials. It operates on the principle that under the action of a high electric field a solution is extruded electrospun. Once the voltage is sufficiently high, a charged stream of matter is ejected following a rather complicated loop and 3D spiral deployment trajectory (Rebouillat \& Pla 2013). During this, the solvent evaporates leaving behind randomly oriented nanofibers accumulating on the collector (Fang et al., 1997). For visualizing morphological features of the electrospun nanofibers different parameters such as electric field strength, tip-to-collector distance, solution feed rate and composition are used. To produce cellulose nanofibres by electrospinning technique have been used by ( Frey \& Joo., 2005) where cellulose fibers have been dissolved in solvents, such as ethylene diamine, with a salt selected from the group consisting of potassium thiocyanate, potassium iodide and mixtures thereof, the salt being present at their saturation points.

\section{Mechanical Processes}

Different mechanical processes have been used to produce microfibrillated cellulose and cellulose nanofibres. These include refining followed by high-pressure homogenization, cryocrushing, grinding, and high intensity ultrasonic treatments.

\section{Refining and High pressure homogenization}

Refining is a pretreatment before high pressure homogenization (Stenstad et al., 2008). For refining to be carried out, a disk refiner is generally used in which a diluted cellulosic suspension is forced through a gap between a rotor and stator. The disks surfaces are grooved and fitted with bars to subject the fibers to repeated cyclic frictional stresses. This mechanical treatment leads to irreversible alterations in the fibres, increasing their bonding potential by modification in their morphology and size (Herrick et al., 1983).

High pressure homogenization is a process in which a large pressure drop facilitated the micro fibrillation (Davoudpour et al., 2015; Khalil et al., 2014). The dilute cellulose slurry previously treated by refining are pumped at high pressure into a vessel through very small nozzle

\section{Volume 6 Issue 12, December 2017}




\section{International Journal of Science and Research (IJSR) \\ ISSN (Online): 2319-7064}

Index Copernicus Value (2016): 79.57 | Impact Factor (2015): 6.391

and fed through a spring loaded valve. As this valve opens and closes at a fast rate, the fibers are exposed to a large pressure drop with shear and impact forces which alongwith high velocity reduce the size of fibers to nanoscale (Frone, et al., 2011). High pressure homogenization is among the proficient methods of refining cellulosic fibres because of its high efficiency, simplicity and without organic solvents requirement (Keeratiurai \& Corredig, 2009).

\section{Cryocrushing}

Cryocrushing is an alternative method for producing cellulose nanofibers (Chakraborty et al., 2005). In the course of action water swollen cellulosic fibers are immerse in liquid nitrogen followed by crushing with mortar and pestle (Frone et al., 2011). Under high impact and shear forces the ice crystals exert pressure on the cell wall leading to rupture of cell wall of frozen cellulosic fibres and thus, liberating nanofibers (Siró \& Plackett, 2010; Wang \& Sain 2007a; Wang \& Sain 2007b).

\section{Grinding}

Grinding is another approach to liberate cellulose nanofibers by rupturing cellulose. The cellulose suspension is passed between the static and the rotating grinding stones of the grinder set at $\sim 1500 \mathrm{rpm}$. In this process, the cell wall structure and hydrogen bond is broken down by the shearing forces generating individual cellulose nanofibers (Abe et al., 2007; Iwamoto et al., 2005; Siró \& Plackett, 2010).

\section{High intensity ultrasonication}

High intensity ultrasonication is a mechanical process which promotes the isolation of cellulose nanofibres with oscillating power and hydrodynamic forces of ultrasound (Cheng et al., 2009). In this process, cavitation leads to a powerful mechanical oscillating power and when molecules absorb ultrasonic energy (Chen et al., 2013) high intensive wave aids in formation and expansion of microscopic gas bubbles.

\section{Microfluidization}

Microfluidization is the process similar to high pressure homogenization which can be used to produce cellulose nanofibres. Microfluidizer includes intensifier pump to increase the pressure and interaction chamber to defibrillate the fibers using shear and impact forces against colliding streams and the channel walls (Ferrer et al., 2012). Aspect ratio of cellulose fibers increases when they pass through the microfludizer (Lee et al. (2009).

\section{Steam explosion}

Steam explosion is a thermo mechanical processe. Due to the high pressure, steam penetrates into the cellulose fibers and shear force is generated by sudden pressure release which hydrolyze the glycosidic and hydrogen bonds resulting in the formation of cellulose nanofibers (Giri \& Adhikari, 2013: Cherian et al., 2010).

\section{Chemical Treatment}

Chemical treatment is the most efficient and easy method to isolate cellulose nanofibres. Alkali treatment, bleaching treatment and acid hydrolysis together disintegrate the cellulosic fibres to nanofibres. Different alkalis remove hemicelluloses and lignin thereby purifies the cellulose. Bleaching agents remove remaining hemicellulose and lignin (Kaur et al., 2017). Oxidative fragmentation of lignin takes place and some of the lignin form lignin chloride which is easily dissolvable. Highest percent of cellulose content is observed after bleaching. Acid hydrolysis induces individualization of microfibrils from the cell wall structure. With $\mathrm{H}_{2} \mathrm{SO}_{4}$, surface charged sulfates are formed, promoting the dispersion of nanocrystals ( Revol et al., 1992). With $\mathrm{H}_{2} \mathrm{SO}_{4}$ aggregation of Cellulose nanofibres has been observed. Combination of $\mathrm{H}_{2} \mathrm{SO}_{4}$ and $\mathrm{HCl}$ during hydrolysis generates spherical nanoparticles due to less sulfate groups on their surface with improved thermal stability (Wang et al., 2007).

\section{Characterization}

Conventionally, microscopic methods have been used as advantageous tool to analyze the appearance, morphology, sizes and shapes of microfibres and cellulose nanofibres produced from various cellulosic raw materials ( Kangas et al., 2014; Abe et al. 2007; Chakraborthy et al. 2005; Cheng et al. 2010; Jonoobi et al. 2009; Kaushik, Singh 2011; Pääkkö et al. 2007; Wang et al. 2012). The different techniques are (i) Scanning electron Microscopy (SEM), (ii) Field emission scanning electron Microscopy (FESEM), (iii)Transmission electron Microscopy (TEM), (iv) Atomic Force Microscopy (AFM), (v)X-ray diffraction (XRD), (vi) Fourier transform infrared (FTIR) spectroscopy, (vii)Particle size measurement (DLS) and (viii)Thermogravimetric analysis (TGA).

The surface morphology of cellulose nanofibres is generally analysed by scanning electron microscopy (SEM). In this technique samples are placed on the aluminium stub and incubated in the oven at $60^{\circ} \mathrm{C}$. Then the samples are coated with gold using a vaccum sputter coater. The accelerating voltage taken as $15 \mathrm{kV}$. FE-SEM imaging can also be achieved by using low acceleration voltages without the conductive layer. The morphology of the regenerated cellulose nanofibres can also be carried out by transmission electron microscopy (TEM). A drop of a dilute aqueous suspension $(0.1 \mathrm{wt} \%)$ is deposited on the surface of a copper grid coated with a thin carbon film. The accelerating voltage to be kept as $100-120 \mathrm{kV}$. Surface topography and morphology can also be determined by atomic force microscopy (AFM) using tip broadening effect where usually a drop of dilute suspension is placed on a mica surface and left to dry. The structural properties of the cellulose nanofibres like size and crystallinity index can be characterized using x-ray diffraction. The thermal stability of cellulose nanofibres can be determined by thermogravimetric analysis. Decomposition of fibres occurs at different temperatures. Fourier transform infrared spectroscopy measurements are carried out with finely ground sample is mixed with potassium bromide, $\mathrm{KBr}$ which is then compressed to 


\section{International Journal of Science and Research (IJSR) \\ ISSN (Online): 2319-7064 \\ Index Copernicus Value (2016): 79.57 | Impact Factor (2015): 6.391}

pellet form and analysis is carried out within the wave number range of $400-4000 \mathrm{~cm}^{-1}$ to access the chemical changes occur during the process (Kangas et al., 2014; Abe et al. 2007; Henriksson et al. 2008; Johansson et al. 2011; Pääkkö et al. 2007).

\section{Conclusion}

Nanotechnology has the ability to manipulate and acquaintance at microscopic stratum. Bio-based nanocellulose has been widely considered as one of the most promising nanomaterials, which has phenomenal applications in industrial sector and in different fields. Nanocellulose is an environmental-friendly material that could serve as an indispensable renewable resource for progressive revitalization which has no harmful effects on human's health and on our environment. This review has provided an explanation of several aspects that are important for understanding of various nanomaterials.

\section{References}

[1] Abraham, E., Deepa, B., Pothan, L. A., Jacob, M., Thomas, S., Cvelbar, U., \& Anandjiwala, R. (2011). Extraction of nanocellulose fibrils from lignocellulosic fibres: a novel approach. Carbohydrate Polymers, 86(4), 1468-1475.

[2] Abe, K., Iwamoto, S., \&Yano, H. (2007). Obtaining cellulose nanofibers with a uniform width of $15 \mathrm{~nm}$ from wood. Biomacromolecules, 8, 3276-3278.

[3] Alemdar, A., \& Sain, M. (2008). Isolation and characterization of nanofibers from agricultural residues-Wheat straw and soy hulls. Bioresource technology, 99(6), 1664-1671.

[4] Azizi Samir, M. A. S., Alloin, F., \& Dufresne, A. (2005). Review of recent research into cellulosic whiskers, their properties and their application in nanocomposite field. Biomacromolecules, 6(2), 612 626.

[5] Azeredo, H. M., Rosa, M. F., \& Mattoso, L. H. C. (2016). Nanocellulose in bio-based food packaging applications. Industrial Crops and Products, 97, 664671.

[6] Brinchi, L., Cotana, F., Fortunati, E., \& Kenny, J. M. (2013). Production of nanocrystalline cellulose from lignocellulosic biomass: technology and applications. Carbohydrate Polymers, 94(1), 154-169.

[7] Chakraborty, A., Sain, M., \& Kortschot, M. (2005). Cellulose microfibrils: A novel method of preparation using high shear refining and cryocrushing. Holzforschung, 59, 102-107.

[8] Chen, P., Yu, H., Liu, Y., Chen, W., Wang, X., \& Ouyang, M. (2013). Concentration effects on the isolation and dynamic rheological behavior of cellulose nanofibers via ultrasonic processing. Cellulose, 20, 149-157.

[9] Cheng, Q., Wang, S., \& Rials, T. G. (2009). Poly (vinyl alcohol) nanocomposites reinforced with cellulose fibrils isolated by high intensity ultrasonication. Composites: Part A, 40, 218-224.

[10]Cheng, Q., Wang, S., \& Han, Q. (2010). Novel process for isolating fibrils from cellulose fibers by high-intensity ultrasonication. II. Fibril characterization. Journal of Applied Polymer Science, 115(5), 2756-2762.

[11]Cherian, B. M., Leão, A. L., de Souza, S. F., Thomas, S., Pothan, L. A., \& Kottaisamy, M. (2010). Isolation of nanocellulose from pineapple leaf fibres by steam explosion. Carbohydrate Polymers, 81(3), 720-725.

[12] Chirayil, C. J., Joy, J., Mathew, L., Mozetic, M., Koetz, J., \& Thomas, S. (2014). Isolation and characterization of cellulose nanofibrils from Helicteres isora plant. Industrial Crops and Products, 59, 27-34.

[13] Chirayil, C. J., Mathew, L., \& Thomas, S. (2014). Review of recent research in nano cellulose preparation from different lignocellulosic fibers. Reviews on Advanced Materials Science, 37, 20-28.

[14] Christoforou, T., \& Doumanidis, C. (2010). Biodegradable cellulose acetate nanofiber fabrication via electrospinning. Journal of nanoscience and nanotechnology, 10(9), 6226-6233.

[15] de Souza Lima, M. M., \& Borsali, R. (2004). Rod like cellulose microcrystals: structure, properties, and applications. Macromolecular Rapid Communications, 25(7), 771-787

[16] Davoudpour, Y., Hossain, S., Khalil, H. A., Haafiz, M. M., Ishak, Z. M., Hassan, A., \& Sarker, Z. I. (2015). Optimization of high pressure homogenization parameters for the isolation of cellulosic nanofibers using response surface methodology. Industrial Crops and Products, 74, 381-387.

[17] Dujardin, E., Blaseby, M., \& Mann, S. (2003). Synthesis of mesoporous silica by sol-gel mineralisation of cellulose nanorod nematic suspensions. Journal of Material Chemistry, 13, 696699.

[18]Eichhorn, S.J., Baillie, C. A., Zafeiropoulos, N., Mwaikambo, L. Y., Ansell, M. P., Dufresne, A,. Entwistle, K. M., Herrera-Franco, P. J., Escamilla, G. C., Groom, L., Hu- gues, M., Hill, C., Rials T. G., \& Wild, P. M. (2001). Review: current international research into cellulosic fibres and composites. Journal of Materials Science, 36(9), 165-188.

[19]Eichhorn, S. J., Dufresne, A., Aranguren, M., Marcovich, N. E., Capadona, J. R., Rowan, S. J., Weder, C., Thielemans, W., Roman, M., Renneckar, S., Gindl, W., Veigel, S., Keckes, J., Yano, H., Abe, K., Nogi, M., Nakagaito , A.N., Mangalam , A., Simonsen, J., Benight, A.S., Bismarck, A., Berglund L.A., Peijs, T.\& Gindl, W. (2010). Current international research into cellulose nanofibres and nanocomposites. Journal of materials science, 45(1), $1-33$

[20]Elias, N., Chandren, S., Attan, N., Mahat, N. A., Razak, F. I. A., Jamalis, J., \& Wahab, R. A. (2017). Structure and properties of oil palm-based nanocellulose reinforced chitosan nanocomposite for efficient synthesis of butyl butyrate.Carbohydrate polymers, 176, 281-292.

[21]Fahma, F., Iwamoto, S., Hori, N., Iwata, T., \& Takemura, A. (2010). Isolation, preparation, and characterization of nanofibers from oil palm emptyfruit-bunch (OPEFB).Cellulose, 17(5), 977-985. 


\section{International Journal of Science and Research (IJSR) \\ ISSN (Online): 2319-7064 \\ Index Copernicus Value (2016): 79.57 | Impact Factor (2015): 6.391}

[22]Fang, X. D. H. R., \& Reneker, D. H. (1997). DNA fibers by electrospinning. Journal of Macromolecular Science, Part B: Physics, 36(2), 169-173.

[23]Ferrer, A., Filpponen, I., Rodríguez, A., Laine, J., \& Rojas, O. J. (2012). Valorization of residual Empty Palm Fruit Bunch Fibers (EPFBF) by microfluidization: Production of nanofibrillated cellulose and EPFBF nanopaper. Bioresource Technology, 125, 249-255.

[24] Frone, A. N., Panaitescu, D. M., \& Donescu, D. (2011). Some aspects concerning the isolation of cellulose micro and nanofibers. UPB Buletin Stiintific, Series B: Chemistry and Materials Science, 73(2), 133-152.

[25]Frey, M. \& Joo, Y. L. (2005). Cellulose Solution in Novel Solvent and Electrospinning Thereof. US2005247236A1, 2005.

[26] Giri,J. \& Adhikari,R. (2013). A brief review on extraction of nanocellulose and its application. Bibechana A Multidisciplinary Journal of Science, Technology and Mathematics , 9, 81-87.

[27] García, A., Gandini, A., Labidi, J., Belgacem, N., \& Bras, J. (2016). Industrial and crop wastes: A new source for nanocellulose biorefinery. Industrial Crops and Products, 93, 26-38.

[28] Henriksson, M., Henriksson, G., Berglund, L. A., \& Lindström, T. (2007). An environmentally friendly method for enzyme-assisted preparation of microfibrillated cellulose (MFC) nanofibers. European Polymer Journal, 43(8), 3434-3441.

[29] Henriksson, M., Berglund, L. A., Lindstrom, T., \& Nishino, T. (2008). Cellulose nanopaper structures of high toughness. Biomacromolecules, 9, 1579-1585.

[30]Herrick, F. W., Casebier, R. L., Hamilton, J. K., \& Sandberg, K. R. (1983). Microfibrillated cellulose: morphology and accessibility. Journal of Applied Polymer Science, 37, 797-813.

[31]Horn, S. J., Vaaje-Kolstad, G., Westereng, B., \& Eijsink, V. (2012). Novel enzymes for the degradation of cellulose. Biotechnology for biofuels, 5(1), 45.

[32] Iwamoto, S., Nakagaito, A. N., Yano, H., \& Nogi, M. (2005). Optically transparent com-posites reinforced with plant fiber-based nanofibers. Applied Physics A: Material Science Process, 81, 1109-1112.

[33] Iwamoto, S., Isogai, A., \& Iwata, T. (2011). Structure and mechanical properties ofwet-spun fibers made from natural cellulose nanofibers. Biomacromolecules, 12,831-836.

[34] Jabbar, A., Militký, J., Wiener, J., Kale, B. M., Ali, U., \& Rwawiire, S. (2017). Nanocellulose coated woven jute/green epoxy composites: Characterization of mechanical and dynamic mechanical behavior. Composite Structures, 161, 340-349.

[35] Janardhnan, S., \& Sain, M. M. (2007). Isolation of cellulose microfibrils-an enzymatic approach. Bioresources, 1(2), 176-188.

[36] John, M. J., \& Thomas, S. (2008). Biofibres and biocomposites. Carbohydrate polymers, 71(3), 343 364.

[37] Jonoobi, M., Harun, J., Mishra, M., \& Oksman, K. (2009). Chemical composition, crystallinity and thermal degradation of bleached and unbleached kenaf bast (Hibiscus cannabinus) pulp and nanofiber. BioResources, 4(2), 626-639.

[38] Jonoobi, M., Harun, J., Mishra, M., \& Oksman, K. (2009). Chemical composition, crystallinity and thermal degradation of bleached and unbleached kenaf bast (Hibiscus cannabinus) pulp and nanofiber. BioResources, 4(2), 626-639.

[39] Jonoobi, M., Harun, J., Mathew, A. P., Hussein, M. Z. B., \& Oksman, K. (2010). Preparation of cellulose nanofibers with hydrophobic surface characteristics. Cellulose, 17(2), 299-307.

[40] Jonoobi, M., Oladi, R., Davoudpour, Y., Oksman, K., Dufresne, A., Hamzeh, Y., \& Davoodi, R. (2015). Different preparation methods and properties of nanostructured cellulose from various natural resources and residues: a review. Cellulose, 22(2), 935-969.

[41] Kalia, S., Boufi, S., Celli, A., \& Kango, S. (2014). Nanofibrillated cellulose: surface modification and potential applications. Colloid and Polymer Science, 292(1), 5-31.

[42] Kamel, S. (2007). Nanotechnology and its applications in lignocellulosic composites, a mini review. Express Polymer Letters, 1(9), 546-575.

[43] Kangas, H., Lahtinen, P., Sneck, A., Saariaho, A.M., Laitinen, O., \& Hellén, E. (2014). Characterization of fibrillated celluloses. A short review and evaluation of characteristics with a combination of methods . Nordic Pulp \& Paper Research Journal, 29 (1), 129143.

[44] Karim, Z., Afrin, S., Husain, Q., \& Danish, R. (2017). Necessity of enzymatic hydrolysis for production and functionalization of nanocelluloses. Critical reviews in biotechnology, 37(3), 355-370.

[45] Kaushik, A., \& Singh, M. (2011). Isolation and characterization of cellulose nanofibrils from wheat straw using steam explosion coupled with high shear homogenization. Carbohydrate research, 346(1), 7685.

[46] Kaur, M., Kumari, S., \& Sharma, P. (2017). Novel renewable resource based nanocellulose from Wheat Straw: Extraction, Preparation and Characterization. In Proceedings of IEEE NANO Nanotehnology for Instrumentation and Measurement Workshop NANOfIM 2017.

[47] Keeratiurai, M., \& Corredig, M. (2009). Effect of dynamic high pressure homogenization on the aggregation state of soy protein. Journal of Agricultural Food andChemistry, 57, 3556-3562.

[48] Khalil, H. P. S., Davoudpour, Y., Aprilia, N. A., Mustapha, A., Hossain, S., Islam, N., \& Dungani, R. (2014). Nanocellulose-Based Polymer Nanocomposite: Isolation, Characterization and Applications. Nanocellulose Polymer Nanocomposites: Fundamentals and Applications, 273-309.

[49] Khalil, H. A., Davoudpour, Y., Saurabh, C. K., Hossain, M. S., Adnan, A. S., Dungani, R., \& Haafiz, M. K. M. (2016). A review on nanocellulosic fibres as new material for sustainable packaging: Process and applications. Renewable and Sustainable Energy Reviews, 64, 823-836. 


\section{International Journal of Science and Research (IJSR) \\ ISSN (Online): 2319-7064 \\ Index Copernicus Value (2016): 79.57 | Impact Factor (2015): 6.391}

[50] Kukle, S., Gravitis, J., Putnina, A., \& Stikute, A. (2011). The effect of steam explosion treatment on technical hemp fibres. In Proceedings of the 8th International Scientific and Practical Conference, 1, 230-237.

[51] Kumar, A., Negi, Y. S., Choudhary, V., \& Bhardwaj, N. K. (2014). Characterization of cellulose nanocrystals produced by acid-hydrolysis from sugarcane bagasse as agro-waste. Journal of Materials Physics and Chemistry, 2(1), 1-8.

[52] Lee, S. Y., Chun, S. J., Kang, I. A., \& Park, J. Y. D. (2009). Preparation of cellulose nanofibers by highpressure homogenizer and cellulose-based composite films.Journal of Indian Engineering Chemistry, 15, $50-55$.

[53] Mahfoudhi, N., \& Boufi, S. (2016). Nanocellulose as a millennium material with enhancing adsorption capacities. Biodegradable and Biobased Polymers for Environmental and Biomedical Applications, 349383.

[54] Maleki, A., Movahed, H., \& Ravaghi, P. (2017). Magnetic cellulose/Ag as a novel eco-friendly nanobiocomposite to catalyze synthesis of chromenelinked nicotinonitriles. Carbohydrate polymers, 156, 259-267.

[55] Morán, J. I., Alvarez, V. A., Cyras, V. P., \& Vázquez, A. (2008). Extraction of cellulose and preparation of nanocellulose from sisal fibers. Cellulose, 15(1), 149. 159.

[56] Morais, J. P. S., de Freitas Rosa, M., Nascimento, L. D., do Nascimento, D. M., \& Cassales, A. R. (2013). Extraction and characterization of nanocellulose structures from raw cotton linter. Carbohydrate Polymers, 91(1), 229-235.

[57]Pääkkö, M., Ankerfors, M., Kosonen, H., Nykänen, A., Ahola, S., Österberg, M. \& Lindström, T. (2007). Enzymatic hydrolysis combined with mechanical shearing and high-pressure homogenization for nanoscale cellulose fibrils and strong gels. Biomacromolecules, 8(6), 1934-1941.

[58] Rebouillat, S., \& Pla, F. (2013). State of the art manufacturing and engineering of nanocellulose: a review of available data and industrial applications. Journal of Biomaterials and Nanobiotechnology, 4(02), 165.

[59] Revol, J.F., Bradford, H., Giasson, J., Marchessault, R. H., \& Gray, D. G. (1992). Helicoidal self-ordering of cellulose microfibrils in aqueous suspension. International Journal of Biological Macromolecules, 14 (3), 170-172.

[60] Saito, T., Hirota, M., Tamura, N., Kimura, S., Fukuzumi, H. \& Heux, L. (2009). Individualization of nano-sized plant cellulose fibrils by direct surface carboxylation using TEMPO catalyst under neutral conditions. Biomacromolecules, 10, 1992-1996.

[61] Siró, I., \& Plackett, D. (2010). Microfibrillated cellulose and new nanocomposite materials: a review. Cellulose, 17(3), 459-494.

[62] Siqueira, G., Bras, J., \& Dufresne, A. (2010). Cellulosic bionanocomposites: a review of preparation, properties and applications. Polymers, 2(4), 728-765.
[63] Sjöström E. (1993). Wood chemistry fundamentals and applications. Academic Press, New York

[64] Stenstad, P., Andresen, M., Tanem, B. S., \& Stenius, P. (2008). Chemical surface modifications of microfibrillated cellulose. Cellulose, 15, 35-45.

[65] Trache, D., Hussin, M. H., Haafiz, M. M., \& Thakur, V. K. (2017). Recent progress in cellulose nanocrystals: sources and production. Nanoscale, 9(5), $1763-1786$

[66] Wang, B., \& Sain, M. (2007a). Dispersion of soybean stock-based nanofiber in a plastic matrix. Polymer International, 56, 538-546.

[67] Wang, B., \& Sain, M. (2007b). Isolation of nanofibers from soybean source and their reinforcing capability on synthetic polymers. Composite Science and Technology, 67, 2521-2527.

[68] Wang, B., Sain, M., \& Oksman, K. (2007). Study of structural morphology of hemp fiber from the micro to the nanoscale. Applied Composite Materials, 14, 89103.

[69]Xie, J., \& Li, J. (2017). Smart drug delivery system based on nanocelluloses. Journal of Bioresources and Bioproducts, 2(1), 1-3.

[70] Wang, Q. Q., Zhu, J. Y., Gleisner, R., Kuster, T. A., Baxa, U., \& McNeil, S. E. (2012). Morphological development of cellulose fibrils of a bleached eucalyptus pulp by mechanical fibrillation. Cellulose, 19(5), 1631-1643.

[71] Yang, Y., Hu, C., \& Abu-Omar, M. M. (2012). Conversion of glucose into furans in the presence of $\mathrm{AlCl} 3$ in an ethanol-water solvent system. Bioresource technology, 116, 190-194 